CLINICAL STUDY

\title{
Fibroblast growth factor-23 is associated with parathyroid hormone and renal function in a population-based cohort of elderly men
}

Richard Marsell, Elin Grundberg ${ }^{1}$, Tijana Krajisnik ${ }^{1}$, Hans Mallmin, Magnus Karlsson ${ }^{2}$, Dan Mellström ${ }^{3}$ Eric Orwoll ${ }^{4}$, Claes Ohlsson ${ }^{3}$, Kenneth B Jonsson, Östen Ljunggren ${ }^{1}$ and Tobias E Larsson ${ }^{1}$

Department of Surgical Sciences, Uppsala University Hospital, Uppsala, Sweden, ${ }^{1}$ Department of Medical Sciences, Uppsala University Hospital, Ing. 70, 3 tr., UAS, 75185 Uppsala, Sweden, ${ }^{2}$ Clinical and Molecular Osteoporosis Research Unit, Departments of Clinical Sciences and Orthopaedics, Malmö University Hospital, Lund University, 20502, Malmö, Sweden, ${ }^{3}$ Center for Bone Research at the Sahlgrenska Academy, Department of Internal Medicine, Gothenburg University, 41345, Gothenburg, Sweden and ${ }^{4}$ Oregon Health and Science University, Portland, Oregon 97239-3098, USA

(Correspondence should be addressed to T E Larsson; Email: tobias.larsson@medsci.uu.se)

\begin{abstract}
Objective: Fibroblast growth factor-23 (FGF23) is a circulating factor involved in phosphate (Pi) and vitamin D metabolism. Serum FGF23 is increased at later stages of chronic kidney disease due to chronic hyperphosphatemia and decreased renal clearance. Recent studies also indicate that FGF23 may directly regulate the expression of parathyroid hormone (PTH) in vitro. Therefore, the objective of the current study was to determine the relationship between FGF23, PTH, and other biochemistries in vivo in subjects with no history of renal disease.

Design: Serum biochemistries were measured in a subsample of the population-based Swedish part of the MrOS study. In total, 1000 Caucasian men aged 70-80 years were randomly selected from the population.

Methods: Intact FGF23, Pi, calcium, albumin, estimated glomerular filtration rate (eGFR, calculated from cystatin $\mathrm{C}$ ), PTH, and 25(OH) $\mathrm{D}_{3}$ were measured. Association studies were performed using linear univariate and multivariate regression analyses.

Results: The median FGF23 level was $36.6 \mathrm{pg} / \mathrm{ml}$, ranging from 0.63 to $957 \mathrm{pg} / \mathrm{ml}$. There was a significant correlation between $\log$ FGF23 and eGFR $(r=-0.21 ; P<0.00001)$ and $\log$ PTH $(r=0.13 ; P<0.001)$. These variables remained as independent predictors of FGF23 in multivariate analysis. In addition, $\log$ PTH $(\beta=0.082 ; P<0.05)$ and eGFR $(\beta=-0.090 ; P<0.05)$ were associated with log FGF23 in subjects with eGFR $>60 \mathrm{ml} / \mathrm{min}$. Only eGFR $(\beta=-0.35 ; P<0.0001)$ remained as a predictor of $\log$ FGF23 in subjects with eGFR $<60 \mathrm{ml} / \mathrm{min}$.

Conclusions: Serum FGF23 and PTH are associated in vivo, supporting recent findings that FGF23 directly regulates PTH expression in vitro. Additionally, eGFR is associated with FGF23 in subjects with normal or mildly impaired renal function, indicating that GFR may modulate FGF23 levels independent of serum Pi.
\end{abstract}

European Journal of Endocrinology 158 125-129

\section{Introduction}

Fibroblast growth factor-23 (FGF23) is a circulating phosphaturic factor that plays a critical role in renal phosphate $(\mathrm{Pi})$ reabsorption (1). Numerous activating and inactivating mutations in the human FGF23 gene have been identified, causing two clinical disorders of disturbed Pi homeostasis: autosomal dominant hypophosphatemic rickets (OMIM\#193100) (2) and hyperphosphatemic familial tumoral calcinosis (OMIM\#211900) $(3,4)$.

The interaction between FGF23 and parathyroid hormone (PTH) in physiology as well as in states of disease is not completely understood. Importantly, we recently showed that FGF23 negatively regulates PTH mRNA expression and protein secretion in vitro (5). High serum FGF23 in chronic kidney disease (CKD) is a predictor of secondary hyperparathyroidism (6), although it is unknown whether increased FGF23 is a cause of, or a protective response to, an emerging hyperparathyroidism. In addition, overexpression of FGF23 in transgenic mice causes secondary hyperparathyroidism $(7,8)$, which could be due to low calcitriol levels and/or hypocalcemia. Finally, serum FGF23 correlates to PTH in pre-dialysis CKD patients $(9,10)$, and it was also recently shown that FGF23 and PTH were associated in a subgroup of patients with early CKD (10). However, such an association remains to be established in a larger group of subjects with normal or mild impairment of renal function.

The role of FGF23 in CKD has been subject to thorough investigation. Initial reports demonstrated elevated serum FGF23 in CKD, although measurements were performed using an assay detecting both intact, as well as inactive, 
C-terminal FGF23 fragments (11-13). Subsequent studies have revealed that intact FGF23 is also increased in CKD, likely as a response to the prevailing hyperphosphatemia $(9,12,14-16)$. Notably, increments in FGF23 are usually not detected until other imbalances in mineral ion homeostasis are present (14). In this regard, FGF23 is typically elevated by a 1000-fold or more in subjects with end-stage renal disease (ESRD). Thus, there is a clear association between FGF23 and glomerular filtration rate (GFR) in ESRD $(10-12,14,16)$. It is unknown whether FGF23 and GFR are associated in subjects with normal or mildly compromised renal function.

In the current study, we sought to explore the relationship between intact FGF23, PTH, renal function, and other serum biochemistries in vivo, employing a large population-based cohort.

\section{Methods}

\section{The Swedish MrOS study in Uppsala}

The MrOS study is an international multicenter prospective fracture epidemiology investigation, involving elderly men from Hong Kong, USA, and Sweden. The Swedish part consists of 3016 men aged 70-80 years (17) of which 1000 participants were recruited at Uppsala University Hospital. The participants were randomly selected from the population registry and invited by mail. To be eligible for the study, the subjects had to be able to walk without aid and aged 70-80 years. At the clinic visit, participants completed questionnaires about medical history, current medication use, and lifestyle characteristics. Height and weight were measured and blood samples were collected for biochemical analyses. Out of the 1000 individuals included in Uppsala, 86 subjects were excluded from the present study due to serum sample inaccessibility. Accordingly, the total number of serum samples analyzed in this study was 914. Informed consent was obtained from all subjects, and the study was approved by the local ethics committees (ethical approval number; Ups 01-057) and conducted in accordance with the guidelines in The Declaration of Helsinki.

\section{Serum biochemistry}

Serum Pi, calcium, albumin, and cystatin $C$ were assessed by standard protocols at the department of clinical chemistry at the Uppsala University Hospital. Serum samples were collected from each individual at a single time point and kept at $-70{ }^{\circ} \mathrm{C}$ until analysis. Calcium levels presented within this paper were corrected for albumin concentration as follows: calcium (corrected) $=$ calcium-(0.018(albumin-42)). GFR was indirectly calculated using the following estimate: GFR $=$ $\left(79.901{\text { (cystatin } C)^{-1.4389}}\right.$ ). PTH levels were analyzed using the Immulite 2000 Intact PTH Assay (Diagnostic Products Corporation, Los Angeles, CA, USA) and $25(\mathrm{OH}) \mathrm{D}_{3}$ was measured on the Nichols Advantage automated assay system (Nichols Institute Diagnostics, San Juan Capistrano, CA, USA). Intact FGF23 concentrations were measured using an ELISA according to manufacturer's protocol (Kainos Laboratories Int'l, Tokyo, Japan) (18). This second-generation, two-site, MAB ELISA has previously been shown to recognize only the biologically active, intact FGF23 protein, but no inactive C-terminal FGF23 fragments. Repeated analysis revealed degradation or measurement error in a small number of samples that was excluded from the subsequent analyses: FGF23 $(n=10)$ and PTH $(n=2)$.

\section{Statistical analysis}

All statistical analyses were performed using STATISTICA software (StatSoft Inc., Tulsa, OK, USA). Univariate correlation analyses were used where the Pearson's correlation coefficient, $r$, measured the degree of linear relationship between the two normally distributed continuous variables. In order to assess how good the predictor variable is in explaining the variability of the target variable, simple linear regression analysis was used. The coefficient of determination, $R^{2}$, is the proportion of the variability observed in the data that is explained by the regression line. Multiple linear regression analysis was used to investigate the relationship among the target and several independent predictor variables simultaneously. It was further used to define the relative contributions of the independent

Table 1 Summary of cohort characteristics. Significant differences between the groups stratified for renal function are highlighted in bold.

\begin{tabular}{|c|c|c|c|c|}
\hline Variables & Reference range & All subjects & GFR $>60 \mathrm{ml} / \mathrm{min}$ & $\mathbf{G F R}<\mathbf{6 0} \mathrm{ml} / \mathrm{min}$ \\
\hline $\begin{array}{l}\text { Age (years) } \\
\text { Height }(\mathrm{mm}) \\
\text { Weight }(\mathrm{kg})\end{array}$ & & $\begin{array}{l}n=1000 \\
75.4 \pm 3.1 \\
1744 \pm 66 \\
80.7 \pm 12\end{array}$ & $\begin{array}{l}n=703 \\
75.9 \pm 3.2 \\
1743 \pm 67 \\
80.6 \pm 12.2\end{array}$ & $\begin{array}{l}\boldsymbol{n}=\mathbf{2 1 1} \\
74.4 \pm 2.7 \\
1745 \pm 63 \\
81.2 \pm 11.7\end{array}$ \\
\hline $\begin{array}{l}\text { Biochemistry } \\
\text { FGF23 }(\mathrm{pg} / \mathrm{ml}) \\
\text { Phosphate }(\mathrm{mmol} / \mathrm{l}) \\
\text { Calcium }(\mathrm{mmol} / \mathrm{l}) \\
\text { GFR }\left(\mathrm{ml} / \mathrm{min} \mathrm{per} 1.73 \mathrm{~m}^{2}\right) \\
\text { PTH }(\mathrm{pmol} / \mathrm{ml}) \\
25(\mathrm{OH}) \mathrm{D}_{3}(\mathrm{nmol} / \mathrm{ml})\end{array}$ & $\begin{array}{l}0.75-1.4 \\
2.15-2.50 \\
>100 \\
1.3-7.6 \\
15-100\end{array}$ & $\begin{array}{l}n=914 \\
44.1 \pm 54.1 \\
1.12 \pm 0.17 \\
2.46 \pm 0.11 \\
75.9 \pm 22.2 \\
3.8 \pm 2.0 \\
76.5 \pm 26\end{array}$ & $\begin{array}{l}n=703 \\
42.0 \pm 58.7 \\
1.11 \pm 0.16 \\
2.45 \pm 0.10 \\
84.5 \pm 17.0 \\
3.6 \pm 1.7 \\
77.7 \pm 25.1\end{array}$ & $\begin{array}{l}n=211 \\
51.2 \pm 34.0^{\star} \\
1.15 \pm 0.19^{\star} \\
2.50 \pm 0.13^{\dagger} \\
47.3 \pm 10.2^{\dagger} \\
4.6 \pm 2.8^{\dagger} \\
77.8 \pm 29.6\end{array}$ \\
\hline
\end{tabular}

${ }^{*} \boldsymbol{P}<0.01 ;{ }^{\dagger} \boldsymbol{P}<0.001$. 


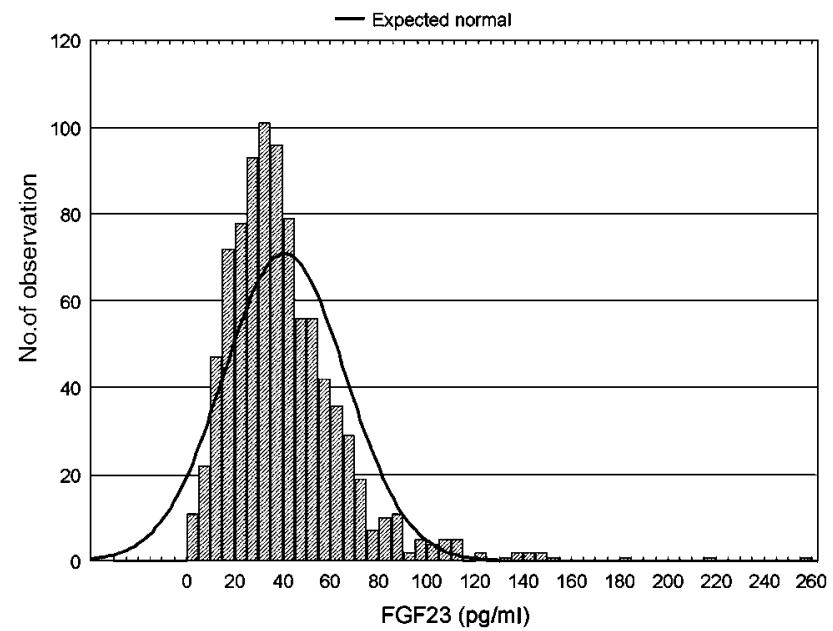

Figure 1 Distribution of intact FGF23 levels in an elderly male population. Median value of FGF23 is $36.6 \mathrm{pg} / \mathrm{ml}$.

variables to the variation in the target variable. The adjusted $R^{2}$ was used in the multiple regression analysis and takes into account the number of terms in the model. Comparisons of biochemical changes between groups were performed using ANOVA followed by Tukey's HSD post hoc test. For all analyses, standardized $\beta$ values are presented and a $P$ value $<0.05$ was considered as statistically significant.

\section{Results}

\section{Serum levels of FGF23}

The clinical characteristics of the cohort are presented in Table 1. Median value of serum intact FGF23 was $36.6 \mathrm{pg} / \mathrm{ml}$ ranging from 0.63 to $957 \mathrm{pg} / \mathrm{ml}$. The distribution of FGF23, excluding five outliers ranging

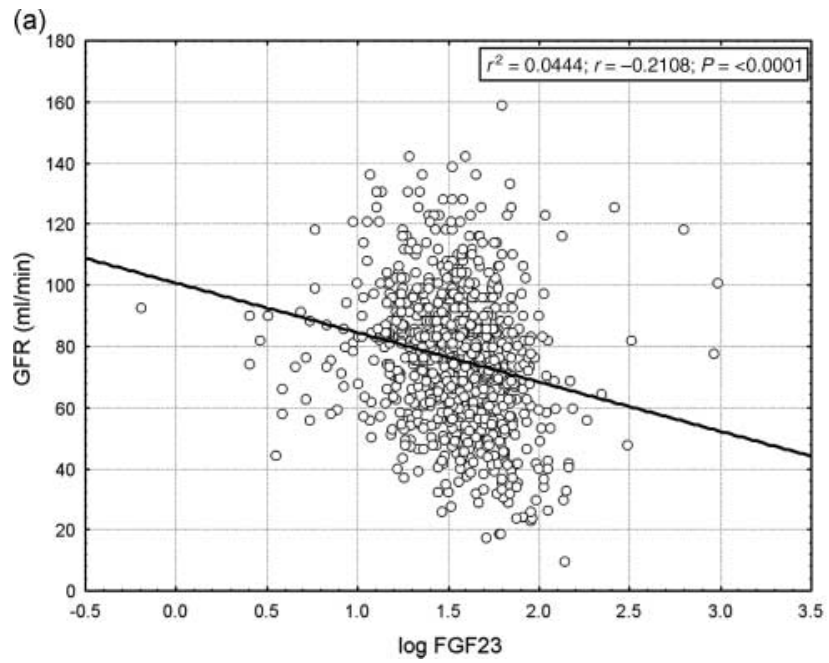

from 305 to $957 \mathrm{pg} / \mathrm{ml}$, is shown in Fig. 1. FGF23, as well as PTH levels, did not reveal a Gaussian distribution and were therefore transformed into log 10-values for regression analysis.

\section{Univariate analyses of FGF23 and biochemical variables}

To determine the co-variance between FGF23 and other serum biochemistries, a general linear regression model was applied. Univariate regression results are presented in Fig. 2a and b. A negative correlation between log FGF23 and eGFR was found $(r=-0.21 ; P<0.00001$; Fig. 2a), where eGFR explained $4.3 \%$ of $\log$ FGF23. Additionally, there was a significant and positive correlation between $\log$ FGF23 and $\log$ PTH $(r=0.13 ; P<0.001$; Fig. $2 b)$, indicating that $\log$ PTH explained $1.6 \%$ of variations in $\log$ FGF23. No significant correlation between $\log$ FGF23 and $\mathrm{Pi}(P=0.75)$, calcium $(P=0.12)$ or $25(\mathrm{OH}) \mathrm{D} 3(P=0.09)$ was observed. Notably, the $[\mathrm{Ca} \times \mathrm{Pi}]$ product is a predictor of FGF23 in CKD (19). We did not find any significant correlation between log FGF 23 and $[\mathrm{Ca} \times \mathrm{Pi}]$ product in our cohort $(P=0.93)$.

\section{Multivariate analyses of FGF23 and biochemical variables}

To establish the relative contribution of explanatory variable for $\log$ FGF23, we performed a multivariate regression analysis with $\mathrm{Pi}$, calcium, eGFR, $\log \mathrm{PTH}$, and $25(\mathrm{OH}) \mathrm{D} 3$ as independent variables. Notably, eGFR $(\beta=-0.19, P<0.00001)$ and $\log$ PTH $(\beta=0.08$, $P=0.020$ ) remained as significant explanatory variables for $\log$ FGF23. Pi, calcium, and $25(\mathrm{OH}) \mathrm{D}_{3}$ similarly failed to influence log FGF23 in this model (Table 2).

We further analyzed subjects stratified for renal function. Multivariate regression analysis in subjects

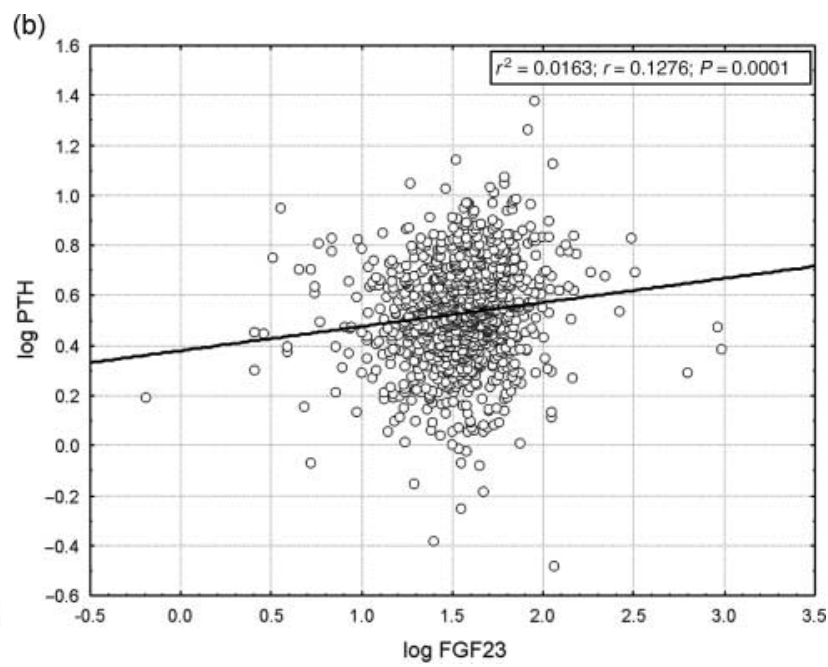

Figure 2 Univariate regression analysis of log FGF23 co-variance with (a) eGFR and (b) log PTH. 
Table 2 Linear univariate and multivariate regression analysis of all study subjects and log fibroblast growth factor-23 (FGF23) levels as dependent variable.

\begin{tabular}{lcccc}
\hline $\boldsymbol{n}=\mathbf{9 1 4}$ & $\boldsymbol{r}$ value & $\boldsymbol{P}$ value & $\boldsymbol{\beta}$ value & $\boldsymbol{P}$ value \\
\hline Phosphate & -0.011 & 0.75 & -0.039 & 0.27 \\
Calcium & 0.051 & 0.12 & 0.012 & 0.74 \\
eGFR & -0.21 & $<\mathbf{0 . 0 0 0 0 1}$ & -0.19 & $<\mathbf{0 . 0 0 0 0 0 1}$ \\
log PTH & 0.13 & $<\mathbf{0 . 0 0 1}$ & 0.080 & $<\mathbf{0 . 0 5}$ \\
25(OH)D3 & -0.058 & 0.094 & -0.055 & 0.10 \\
\hline
\end{tabular}

Significant $P$ values are bolded.

with eGFR $>60 \mathrm{ml} / \mathrm{min}(n=703)$ revealed that eGFR $(\beta=-0.09 ; \quad P=0.022)$ and $\log$ PTH $(\beta=0.08$; $P=0.036)$ remained as explanatory variables for $\log$ FGF23 (Table 3). In contrast, eGFR $(\beta=-0.35$; $P<0.0001)$ was the only predictor of log FGF23 in subjects with eGFR $<60 \mathrm{ml} / \mathrm{min}$ (Table 4). All biochemical variables, except $25(\mathrm{OH}) \mathrm{D} 3$, were statistically different in the two groups stratified for renal function (Table 1).

\section{Multivariate analyses of PTH and biochemical variables}

Since we found an association between FGF23 and $\mathrm{PTH}$, we sought to analyze other variables associated with $\log$ PTH. Multivariate regression analysis with Pi, calcium, GFR, 25(OH)D $\mathrm{D}_{3}$, and log FGF23 as independent variables revealed that log FGF23, $(\beta=0.08 ; P=0.020)$, Pi $(\beta=-0.08 ; P=0.026)$, and eGFR $(\beta=-0.17$; $P<0.00001)$ were explanatory variables for $\log$ PTH.

\section{Discussion}

In the study cohort described herein, we found an independent and positive association between serum FGF23 and PTH. This association has not previously been described in subjects without CKD. The sample size in the current study is also of greater magnitude than any previous published data on serum FGF23 levels, increasing the probability of detecting such an association. Our data could imply a physiological co-regulation of FGF23 and PTH in vivo. Further support for this hypothesis arose from our recent observations that FGF23 potently

Table 3 Linear univariate and multivariate regression analysis of subjects with glomerular filtration rate (GFR) $>60 \mathrm{ml} / \mathrm{min}$ and $\mathrm{log}$ fibroblast growth factor-23 (FGF23) as dependent variable.

\begin{tabular}{lcrrr}
\hline $\boldsymbol{n}=\mathbf{7 0 3}$ & $\boldsymbol{r}$ value & $\boldsymbol{P}$ value & $\boldsymbol{\beta}$ value & $\boldsymbol{P}$ value \\
\hline Phosphate & -0.006 & 0.87 & -0.034 & 0.40 \\
Calcium & 0.062 & 0.10 & 0.046 & 0.26 \\
eGFR & -0.10 & $<\mathbf{0 . 0 1}$ & -0.090 & $<\mathbf{0 . 0 5}$ \\
log $\mathrm{PTH}$ & 0.10 & $<\mathbf{0 . 0 1}$ & 0.082 & $<\mathbf{0 . 0 5}$ \\
25(OH) $\mathrm{D}_{3}$ & -0.046 & 0.24 & -0.043 & 0.27 \\
\hline
\end{tabular}

Significant $P$ values are bolded.
Table 4 Linear univariate and multivariate regression analysis of subjects with estimated glomerular filtration rate (eGFR) $<60 \mathrm{ml} / \mathrm{min}$ and log fibroblast growth factor-23 (FGF23) as dependent variable.

\begin{tabular}{lcccc}
\hline $\boldsymbol{n}=\mathbf{2 1 1}$ & $\boldsymbol{r}$ value & $\boldsymbol{P}$ value & $\boldsymbol{\beta}$ value & $\boldsymbol{P}$ value \\
\hline Phosphate & -0.089 & 0.20 & -0.099 & 0.19 \\
Calcium & 0.082 & 0.24 & -0.065 & 0.37 \\
eGFR & -0.34 & $<\mathbf{0 . 0 0 0 0 0 1}$ & -0.35 & $<\mathbf{0 . 0 0 0 1}$ \\
log PTH & 0.11 & 0.11 & -0.27 & 0.73 \\
25(OH)D3 & 0.098 & 0.18 & -0.10 & 0.14 \\
\hline
\end{tabular}

Significant $P$ values are bolded.

decreases PTH mRNA expression and protein secretion in vitro, using primary isolates of bovine parathyroid cells (5). Additionally, one preliminary report showed that injection of PTH in mice increased serum FGF23 levels (20). Thus, it is possible that small and immediate changes in serum FGF23 alter PTH secretion and vice versa, supporting the idea of a bone-parathyroid axis required for maintenance of a proper mineral ion homeostasis.

We also found that eGFR was significantly associated with FGF23, including subjects with eGFR $>60 \mathrm{ml} / \mathrm{min}$. It is previously well established that severely impaired renal function causes increments in serum FGF23, in part due to chronic hyperphosphatemia, but also due to decreased renal clearance of FGF23 $(11,12)$. Because our study subjects have normal serum $\mathrm{Pi}$, we conclude that decreased renal clearance of FGF23 likely proceeds abnormalities in calcium $/ \mathrm{Pi}$ balance present at later stages of CKD. Although a highly significant association, the correlation coefficient for log FGF23 and eGFR is relatively low. Thus, eGFR cannot be used as a reliable predictor of serum FGF23 in patients with normal renal function or in early CKD. Since all participants of the current study were males and displayed a narrow age span, we cannot rule out the possibility that increased age or gender differences contribute to elevated serum FGF 23 in some subjects, even when adjusted for renal function. However, serum FGF23 in previous measured cohorts of healthy controls or CKD subjects did not vary significantly with age or gender $(10,13)$. Finally, the FGF23 values in the current cohort are slightly higher than a previously established reference range in 104 healthy controls for the intact FGF23 ELISA used herein $(28.9 \pm 1.1 \mathrm{pg} / \mathrm{ml}$; mean \pm s.D.) (18). This discrepancy can most likely be attributed to a lower mean eGFR in the subjects used within the present study.

We failed to detect any significant correlation between FGF23 and Pi. Notably, to our knowledge, no correlation between FGF23 and Pi has previously been described in subjects with normal renal function without manipulating dietary Pi intake (21-23). The fact that PTH, but not FGF23, correlates to Pi in our study may also imply that Pi induces changes in serum PTH more rapidly than in FGF23. This is supported by a recent study where dietary Pi load resulted in a rapid increase in PTH, whereas FGF23 remained unchanged during the first $8 \mathrm{~h}(21)$. It would be of interest to determine the relationship between FGF23 
and dietary Pi intake in the cohort used herein, however, these data are unavailable.

FGF23 decreases serum calcitriol in vivo $(1,2)$ and there is an inverse correlation between FGF23 and calcitriol in CKD (14). Therefore, a limitation of this study is the absence of $1,25(\mathrm{OH}) 2 \mathrm{D}_{3}$ measurements. However, we found a trend that $25(\mathrm{OH}) \mathrm{D}_{3}$ was negatively correlated to FGF23, although above the threshold of significance.

In summary, serum FGF23 is independently associated with PTH and renal function in a population-based cohort of elderly men. Our study implies a possible co-regulation of FGF23 and PTH and sheds further light on the regulation of FGF23 in states of normophosphatemia.

\section{Acknowledgements}

We would like to thank Anna-Lena Johansson for technical assistance. This work was supported by the Novo Nordisk Foundation, the Swedish Kidney Foundation, and the Swedish Society of Medicine. T E L and Ö L received lecture fees. The other authors have nothing to declare.

\section{References}

1 Shimada T, Mizutani S, Muto T, Yoneya T, Hino R, Takeda S, Takeuchi Y, Fujita T, Fukumoto S \& Yamashita T. Cloning and characterization of FGF23 as a causative factor of tumor-induced osteomalacia. PNAS 200198 6500-6505.

2 ADHR-Consortium. Autosomal dominant hypophosphataemic rickets is associated with mutations in FGF23. Nature Genetics 200026 345-348.

3 Larsson T, Yu X, Davis SI, Draman MS, Mooney SD, Cullen MJ \& White KE. A novel recessive mutation in fibroblast growth factor-23 causes familial tumoral calcinosis. Journal of Clinical Endocrinology and Metabolism 200590 2424-2427.

4 Benet-Pages A, Orlik P, Strom TM \& Lorenz-Depiereux B. An FGF23 missense mutation causes familial tumoral calcinosis with hyperphosphatemia. Human Molecular Genetics 200514 385-390.

5 Krajisnik T, Bjorklund P, Marsell R, Ljunggren O, Akerstrom G, Jonsson K, Westin G \& Larsson T. FGF23 regulates expression of PTH and 1-alpha hydroxylase in bovine parathyroid cells. Journal of Endocrinology 2007197 125-131.

6 Nakanishi S, Kazama JJ, Nii-Kono T, Omori K, Yamashita T, Fukumoto S, Gejyo F, Shigematsu T \& Fukagawa M. Serum fibroblast growth factor- 23 levels predict the future refractory hyperparathyroidism in dialysis patients. Kidney International 200567 1171-1178.

7 Larsson T, Marsell R, Schipani E, Ohlsson C, Ljunggren O, Tenenhouse HS, Juppner H \& Jonsson KB. Transgenic mice expressing fibroblast growth factor 23 under the control of the alpha1(I) collagen promoter exhibit growth retardation, osteomalacia, and disturbed phosphate homeostasis. Endocrinology 2004145 3087-3094.

8 Bai X, Miao D, Li J, Goltzman D \& Karaplis AC. Transgenic mice overexpressing human fibroblast growth factor 23 (R176Q) delineate a putative role for parathyroid hormone in renal phosphate wasting disorders. Endocrinology 2004145 5269-5279.

9 Shigematsu T, Kazama JJ, Yamashita T, Fukumoto S, Hosoya T, Gejyo F \& Fukagawa M. Possible involvement of circulating fibroblast growth factor 23 in the development of secondary hyperparathyroidism associated with renal insufficiency. American Journal of Kidney Diseases 200444 250-256.
10 Westerberg PA, Linde T, Wikstrom B, Ljunggren O, Stridsberg M \& Larsson TE. Regulation of fibroblast growth factor-23 in chronic kidney disease. Nephrology, Dialysis, Transplantation 200722 3202-3207.

11 Larsson T, Nisbeth U, Ljunggren O, Juppner H \& Jonsson KB. Circulating concentration of FGF-23 increases as renal function declines in patients with chronic kidney disease, but does not change in response to variation in phosphate intake in healthy volunteers. Kidney International $2003642272-2279$.

12 Weber TJ, Liu S, Indridason OS \& Quarles LD. Serum FGF23 levels in normal and disordered phosphorus homeostasis. Journal of Bone and Mineral Research 200318 1227-1234.

13 Jonsson KB, Zahradnik R, Larsson T, White KE, Sugimoto T, Imanishi Y, Yamamoto T, Hampson G, Koshiyama H, Ljunggren O, Oba K, Yang IM, Miyauchi A, Econs MJ, Lavigne J \& Juppner H. Fibroblast growth factor 23 in oncogenic osteomalacia and X-linked hypophosphatemia. New England Journal of Medicine 2003348 1656-1663.

14 Gutierrez O, Isakova T, Rhee E, Shah A, Holmes J, Collerone G, Juppner $\mathrm{H} \&$ Wolf $\mathrm{M}$. Fibroblast growth factor-23 mitigates hyperphosphatemia but accentuates calcitriol deficiency in chronic kidney disease. Journal of the American Society of Nephrology $2005162205-2215$.

15 Yamashita T. Biological activity of FGF-23 and pathophysiologic role in chronic kidney disease. Clinical Calcium 2004 14 760-763.

16 Imanishi $\mathrm{Y}$, Inaba $\mathrm{M}$, Nakatsuka K, Nagasue K, Okuno S, Yoshihara A, Miura M, Miyauchi A, Kobayashi K, Miki T, Shoji T, Ishimura E \& Nishizawa Y. FGF-23 in patients with endstage renal disease on hemodialysis. Kidney International 200465 1943-1946.

17 Mellstrom D, Johnell O, Ljunggren O, Eriksson AL, Lorentzon M, Mallmin H, Holmberg A, Redlund-Johnell I, Orwoll E \& Ohlsson C. Free testosterone is an independent predictor of BMD and prevalent fractures in elderly men: MrOS Sweden. Journal of Bone and Mineral Research 200621 529-535.

18 Yamazaki Y, Okazaki R, Shibata M, Hasegawa Y, Satoh K, Tajima T, Takeuchi Y, Fujita T, Nakahara K, Yamashita T \& Fukumoto S. Increased circulatory level of biologically active fulllength FGF-23 in patients with hypophosphatemic rickets/osteomalacia. Journal of Clinical Endocrinology and Metabolism 200287 4957-4960.

19 Sato T, Tominaga Y, Ueki T, Goto N, Matsuoka S, Katayama A, Haba T, Uchida K, Nakanishi S, Kazama JJ, Gejyo F, Yamashita T \& Fukagawa M. Total parathyroidectomy reduces elevated circulating fibroblast growth factor 23 in advanced secondary hyperparathyroidism. American Journal of Kidney Diseases 2004 44 481-487.

20 Hasegawa H, Shimada T \& Yamazaki Y. Parathyroid-dependent and -indepedent mechanism to elevate serum concentration of FGF-23 (abstract). Journal of the American Society of Nephrology $200415267 \mathrm{~A}$.

21 Nishida Y, Taketani Y, Yamanaka-Okumura H, Imamura F, Taniguchi A, Sato T, Shuto E, Nashiki K, Arai H, Yamamoto H \& Takeda E. Acute effect of oral phosphate loading on serum fibroblast growth factor 23 levels in healthy men. Kidney International $2006 \mathbf{7 0}$ 2141-2147.

22 Antoniucci DM, Yamashita T \& Portale AA. Dietary phosphorus regulates serum fibroblast growth factor- 23 concentrations in healthy men. Journal of Clinical Endocrinology and Metabolism 2006 91 3144-3149.

23 Perwad F, Azam N, Zhang MY, Yamashita T, Tenenhouse HS \& Portale AA. Dietary and serum phosphorus regulate fibroblast growth factor 23 expression and 1,25-dihydroxyvitamin D metabolism in mice. Endocrinology 2005146 5358-5364.

Received 7 August 2007

Accepted 9 September 2007 